\title{
Colorimetric Determination of (Aminoalkyl)indole-containing Synthetic Cannabimimetics
}

\author{
Hasan Durmuş,* Selen Durmazel,* Ayşem Üzer,* Bahar GöKDERe,* Erol ErÇA $\breve{\text {, }} * *$ and \\ Reşat APAK $* * * * \dagger$ \\ *Department of Chemistry, Faculty of Engineering, Istanbul University-Cerrahpaşa, Avcllar, Istanbul 34320, \\ Turkey \\ **Aytar Caddesi, Fecri Ebcioğlu Sokak, No. 6/8, Levent, Istanbul 34340, Turkey \\ ***Turkish Academy of Sciences (TUBA), Piyade St. No. 27, Çankaya, Ankara 06690, Turkey
}

\begin{abstract}
Cannabis is an important industrial plant, in addition to its illicit drug use. Compound $\Delta^{9}$-THC ( $\Delta^{9}$-tetrahydrocannabinol) is mainly responsible for the hallucinogenic effect on humans. The aminoalkylindole group cannabimimetics targets at the same physiological receptors to mimic the analgesic effects of $\Delta^{9}$-THC. Since there is no reliable colorimetric test to detect these synthetic cannabimimetics on site, a simple colorimetric assay for (aminoalkyl)indole group-containing drugs was developed, based on the silica/sulfuric acid-catalyzed Ehrlich reaction of (aminoalkyl)indoles with $p$-dimethylaminobenzaldehyde. The electrophilic substitution reaction of indoles with carbonyl compounds resulting in the formation of bis(indolyl)alkanes in an acid-catalyzed reaction has been used for the first time for their spectrophotometric determination by color change from yellow to purple/blue. The method was statistically validated against liquid chromatography tandem mass spectrometry, and applied to certain (aminoalkyl)indole derivatives, with $0.5-2.5 \mu \mathrm{g} \mathrm{mL}^{-1}$ detection limits for AM-2201, JWH-081, MAM-2201, JWH-018, JWH-210, JWH-122, 5F-PB-22 and XLR-11.
\end{abstract}

Keywords Forensic science, (aminoalkyl)indole, synthetic cannabimimetics, Ehrlich reaction, $p$-dimethylaminobenzaldehyde, colorimetric detection

(Received July 4, 2018; Accepted August 27, 2018; Advance Publication Released Online by J-STAGE September 7, 2018)

\section{Introduction}

Known since ancient times, Marijuana is cultivated today as two main species (Cannabis sativa and Cannabis indica) in almost every region of the world. ${ }^{1}$ There are more than 60 chemical compounds classified as cannabinoids in the cannabis plant. ${ }^{2}$ "Cannabinoid" is a general name given to alkaloids contained in a cannabis plant, and smokeable herbal mixtures containing synthetic cannabimimetics are sold under a common name of "spice" in Europe. ${ }^{3}$ Cannabis is the most widely used plant of abuse ${ }^{4}$ that is considered harmless by some, while others report it as affecting mental health, especially on young people. ${ }^{5}$ $\Delta^{9}$-THC $[((-)-(6 \mathrm{a} R, 10 \mathrm{a} R)-6,6,9$-trimethyl-3-pentyl-6a,7,8,10atetrahydro- $6 H$-benzo[c]chromen-1-ol)], which was isolated from cannabis in 1964, is mainly responsible for the hallucinogenic effect on humans. ${ }^{6-8}$

In 1990s, J. W. Huffman et al. synthesized a series of compounds, briefly known as (aminoalkyl)indoles or JWH (named after J. W. Huffman accomplishing this synthesis). ${ }^{9-12}$ These substances, which have $\Delta^{9}$-THC-like effects and are of non-vegetable origin, are currently called "synthetic cannabinoids". In the early 2000s, the (aminoalkyl)indoles comprised a novel and leading class of cannabinoid receptor agonists consisting of an indole nucleus substituted by an

$\dagger$ To whom correspondence should be addressed.

E-mail: rapak@istanbul.edu.tr aminoalkyl group at position 1 and an aroyl group at position 3 (Fig. 1). Although these (aminoalkyl)indole compounds are structurally different from cannabinoids, it is interesting that they react as a cannabimimetic. ${ }^{13,14}$

In addition to a variety of portable devices used by security forces to detect explosive or narcotic substances, colorimetric methods are the most preferred ones with ease of implementation and low cost. Colorimetric methods are sufficiently selective and sensitive to enable simple and cost-effective detection of various analytes by the naked eye, and usually do not require special labware/technique, lengthy protocols and sophisticated instrumentation. ${ }^{15-18}$ Test kits, which can be purchased commercially, are available for cannabis, heroin, cocaine and amphetamine groups. ${ }^{19-25}$ However, these test kits, which are limited for synthetic cannabinoids, involve non-specific tests ${ }^{26}$ and are non-quantitative. Synthetic cannabinoids, which have a molecular structure similar to $\Delta^{9}$-THC, give positive results to

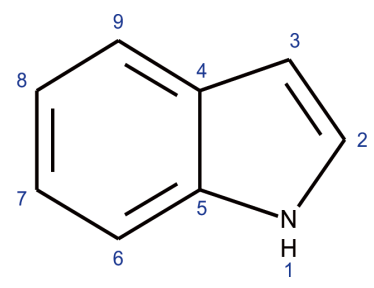

Fig. 1 Chemical structure of indole molecule. 
known marijuana tests (e.g., the Duqeunois-Levine test and Fast Blue $\mathrm{B}$ salt), while non-similar cannabinoids with different structures do not. ${ }^{27}$ Namera et al. evaluated the DuquenoisLevine reagent (i.e. vanillin and acetaldehyde in $\mathrm{EtOH}$ ), used to identify classical cannabinoids, not to be suitable for synthetic cannabimimetics. $^{28}$ Isaacs reported positive results (orange/redorange color formation) for a test made with Brady's reagent containing 2,4-dinitrophenylhydrazine (DNPH) for synthetic cannabimimetics bearing ketone carboxyl group. ${ }^{29}$ There are also many studies based on chromatography for the determination of synthetic cannabinoids containing (aminonaphthyl)indole group. ${ }^{30-32}$ In general, a large majority of these literature studies focus on the identification and quantification of the material encountered for the first time. ${ }^{30,31,33-36}$

The main problem related to the quantitation of synthetic cannabimimetics is the lack of reliable reference materials. The studies carried out in this regard are rather limited. $27,30,37-38$ For this reason, it is important to devise novel practical methods for the determination of various types of synthetic cannabimimetics.

Ehmann used a van Urk-Salkowski reagent containing $p$-dimethylaminobenzaldehyde ( $p$-DMAB), $\mathrm{FeCl}_{3}$ and sulfuric acid for visualizing indole derivatives on thin layer plates. ${ }^{39}$ Utilizing this property of $p$-DMAB, we developed and validated a novel colorimetric method to detect most indole-containing compounds as a widely-used class of synthetic cannabimimetics. The detection principle of this method is the measurement of optical absorbance of the pink-purple or blue colored product that was generated from the reaction of synthetic cannabimimetics with $p$-DMAB in the presence of silica-sulfuric acid catalyst $\left(\mathrm{SSA}, \mathrm{SiO}_{2}-\mathrm{O}-\mathrm{SO}_{3} \mathrm{H}\right)$ at wavelengths of 575 and/or $635 \mathrm{~nm}$. This appears to be a colorimetric method that can be easily used in determining (aminoalkyl)indole-containing synthetic cannabimimetics.

\section{Experimental}

\section{Reagents and chemicals}

All reagents were of analytical reagent grade unless otherwise stated. Ethanol (EtOH), formic acid, $p$-dimethylaminobenzaldehyde ( $p$-DMAB), sulfuric acid, salicylic acid and urea were purchased from Sigma-Aldrich (St. Louis, MO, USA). Mannitol and silica gel $60(0.063-0.200 \mathrm{~mm})$, as well as acetonitrile and methanol for chromatography were obtained from Merck (Darmstadt, Germany). Certified reference materials; AM-2201 (1-[(5-fluoropentyl)-1H-indol-3-yl]-(naphthalen-1-yl)methanone), MAM-2201 [[1-(5-fluoropentyl)1- $H$-indol-3-yl](4-methyl-1naphthalenyl)-methanone], JWH-018 (naphthalen-1-yl(1-pentyl$1 H$-indol-3-yl)methanone), JWH-081 ((4-methoxynaphthalen-1yl)-1-pentylindol-3-yl)methanone), JWH-122 ((4-methylnaphthalen1-yl)-(1-pentylindol-3-yl)methanone) and JWH-210 ((4-ethylnaphthalen-1-yl)(1-pentyl-1 $H$-indol-3-yl)methanone) were purchased from Cayman Chemicals (Ann Arbor, MI).

The non-certified synthetic cannabimimetics; XLR-11 [1-(5-fluoropentyl)-1 $H$-indol-3-yl](2,2,3,3-tetramethylcyclopropyl)methanone and 5F-PB-22 (quinolin-8-yl 1-(5-fluoropentyl)- $1 H$ indole-3-carboxylate) were obtained from Istanbul Police Directorate Crime Laboratory.

\section{Apparatus}

The UV-Visible (UV-Vis) spectra and absorption measurements were recorded in matched Hellma quartz cuvettes using a Shimadzu UV-1800 UV-Vis spectrophotometer. The optical thickness of the cuvettes used in solution-phase measurements was $10 \mathrm{~mm}$. Shimadzu LC-MS/MS 8040 liquid chromatography- tandem mass spectrometer was used to validate the proposed assay.

\section{Preparation of solutions}

The preparation of all solutions used throughout the study is as described in Supporting Information.

Recommended procedure for determining synthetic cannabimimetics including aminoalkylindole functional groups

Twenty miligrams of $\mathrm{SiO}_{2}$ were weighed to a $100 \mathrm{~mL}$-beaker, and $1 \mathrm{~mL}$ of concentrated sulfuric acid $\left(\mathrm{H}_{2} \mathrm{SO}_{4}\right)(98 \%$, w/v) was added to the beaker for immobilizing $\mathrm{H}_{2} \mathrm{SO}_{4}$ on $\mathrm{SiO}_{2}$ surface (silica-sulfuric acid catalyst), and $1 \mathrm{~mL}$ synthetic cannabimimetic sample solution in EtOH (for AM-2201, MAM-2201 and JWHtype synthetic cannabimimetics) or in $\mathrm{MeOH}-\mathrm{H}_{2} \mathrm{O}(70: 30$, v/v, for XLR-11 and 5F-PB-22) was introduced to the mixture in this order. The final mixture was kept at $180^{\circ} \mathrm{C}$ for $5 \mathrm{~min}$. At the end of this time, the beaker was removed from the hot plate, and $1 \mathrm{~mL}$ of a $0.33 \mathrm{~mol} \mathrm{~L}^{-1} p$-DMAB solution was rapidly introduced to the beaker. A color change from yellow to purple or blue was observed. The mixture was taken to a $10 \mathrm{~mL}$ volumetric flask by washing with $\mathrm{EtOH}$.

\section{Optimization of reaction parameters for the recommended method}

The temperature, volume and concentration of $\mathrm{H}_{2} \mathrm{SO}_{4}$, amount of $\mathrm{SiO}_{2}$ and concentration of $p$-DMAB reagent were optimized as described in Supporting Information.

Analytical recovery of synthetic cannabimimetics in the presence of camouflage materials

The proposed method applied to potential camouflage materials (indomethacin, ziprasidone, mannitol, salicylic acid and urea) in combination with $600 \mu \mathrm{g} \mathrm{mL}^{-1}$ (initial concentration) AM-2201 (for details, please see Supporting Information).

\section{$L C-M S / M S$ conditions}

The method of Shimadzu application ${ }^{40}$ for the quantitative analysis of cannabimimetics was followed for validation of the developed method. The LC-MS/MS determination of the synthetic cannabimimetics was described in Supporting Information.

\section{Real sample analysis}

AM-2201-impregnated plant material (Veronica, speedwell) and JWH-018-impregnated plant material, dried Marshmallow leaves which are generally used for impregnation of the drugs, ${ }^{41}$ were tested for real sample analysis as described in Supporting Information.

\section{Statistical analysis}

Descriptive statistical analyses were performed using Excel software (Microsoft Office 2013) for calculating the mean and the standard error of the mean. Results were expressed as \{mean \pm standard deviation (SD) . Method validation against LC-MS/MS ${ }^{40}$ was made by means of Student's $t$ - and $F$-tests.

\section{Results and Discussion}

\section{Evaluation of the color tests existing in the literature}

The analyzed cannabimimetics were tested with the colorimetric reagent DNPH for identifying carbonyl groups, as defined in the literature ${ }^{29}$ reporting an orange-red color reaction for JWH-class cannabinoids, without quantitative results. 


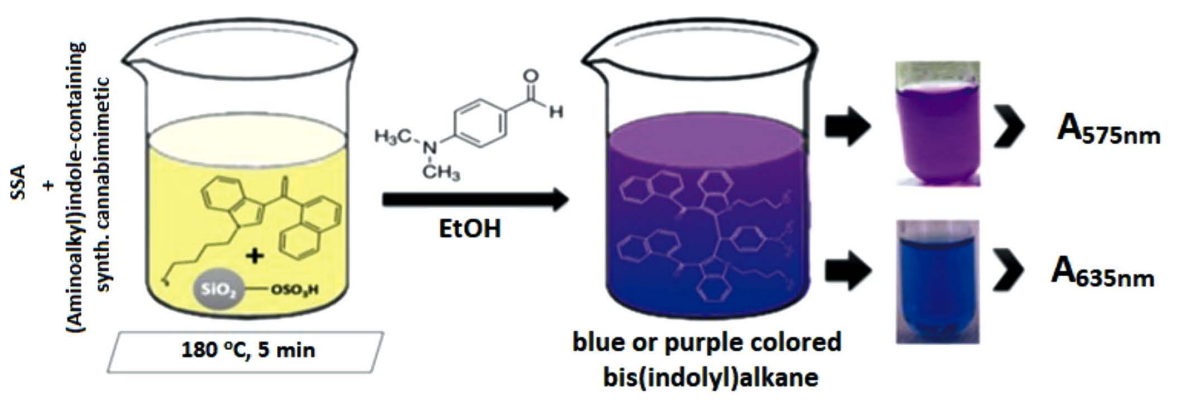

(I)

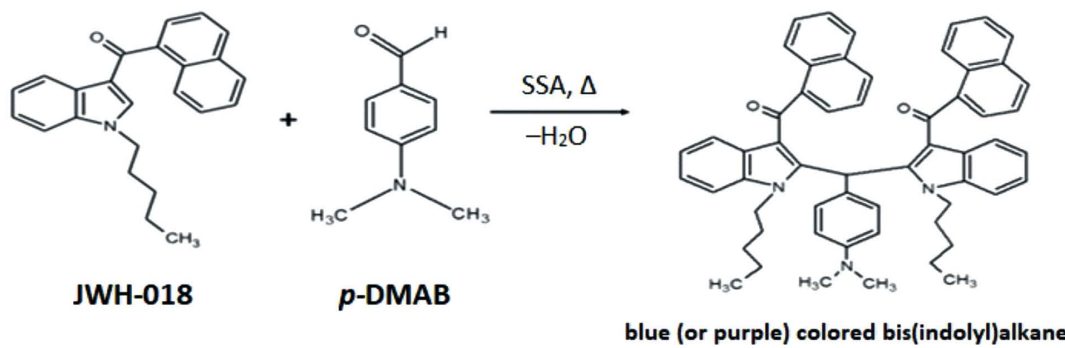

Fig. 2 (I) Schematic presentation of colorimetric detection of (aminoalkyl)indole-containing synthetic cannabimimetics. (II) The proposed mechanism (according to Pore et al. ${ }^{47}$ ) of SSA-catalyzed reaction of JWH-018 with $p$-DMAB.

Our preliminary results with DNPH did not confirm a useful color reaction for cannabimimetic quantitation. In fact, each carbonyl compound has a different reactivity toward DNPH, ${ }^{42}$ and some carbonyls do not react at all due to the unfavorable electronic environment of the carbonyl group, such as the 11keto steroid remaining unreactive to DNPH. ${ }^{43}$ The van Urk reagent (i.e. $p$-dimethylaminobenzaldehyde- $\mathrm{H}_{2} \mathrm{SO}_{4}$ and oxidant), which is used to identify abuse drugs containing indole, also does not work for these compounds.

\section{Plausible reaction mechanism of the proposed method}

The mechanism of the Ehrlich reaction between indole derivatives and $p$-DMAB was originally described in detail by the works of Glenner. ${ }^{44,45}$ "Electron-rich" bicyclic indoles chemically behave in a similar manner to reactive pyrroles with the exception that they most frequently react through the 3 -position (Fig. 1), and seldom through the 2-position in case of unavailability of the 3 -site. ${ }^{46}$

Most colorimetric reactions of forensic interest occur between electron-rich and electron-poor compounds. For example, the indole moiety of lysergic acid diethylamide (LSD) has two modestly electron donating alkyl substituents which may enhance its electron rich properties and realize a reaction with $p$-DMAB in acidic medium. Likewise, psilocin has one moderate electron donating alkyl substituent and one strongly electron donating hydroxyl substituent which, when taken together, may facilitate reaction with acidified $p$-DMAB. On the contrary, certain indole-containing cannabimimetics have one moderate electron donating alkyl substituent (on nitrogen) and one strongly electron withdrawing substituent (a carbonyl) which make them electron-deficient by overall evaluation. ${ }^{29}$ The electrophilic substitution of indoles with carbonyl compounds yields bis(indolyl) alkanes in an acid-catalyzed reaction. In the current research, the in situ synthesis of bis(indolyl) alkanes from electron-rich aminoalkylindolecontaining synthetic cannabimimetics with $p$-DMAB provides a useful tool for the colorimetric determination of these cannabinoids. It was reported that if the indole is 3 -substituted, the electrophilic substitution of $p$-DMAB may occur at C-2 position in acceptable yields. ${ }^{47}$ The possibility of synthesis of 2,2'-bis(indolyl) alkanes was earlier shown to occur with 3 -substituted indoles. ${ }^{48}$ Although the Ehrlich reagent is capable of reacting with indoles at room temperature, aminoalkylindoles require a catalyst for the same reaction carried out at elevated temperature. The silica-sulfuric acid catalyst used in the concerned reaction of this study was prepared by immobilization of $\mathrm{H}_{2} \mathrm{SO}_{4}$ within the pores of $\mathrm{SiO}_{2}{ }^{49} \quad \mathrm{H}_{2} \mathrm{SO}_{4}$ not only acidifies the medium but is also responsible for the dehydration necessary for color development. Temperature is also an indispensable factor affecting the reaction because electrophilic substitution reactions of simple structured indoles with aldehydes/ketones are reported to occur at room temperature, whereas higher temperatures are required for more complex indoles, such as synthetic cannabimimetics. It may be hypothesized that $\mathrm{H}_{2} \mathrm{SO}_{4}$ plays a role here, similar to that observed in an esterification reaction catalyzed by $\mathrm{H}_{2} \mathrm{SO}_{4} \quad$ (e.g., $\quad \mathrm{RCOOH}+\mathrm{R}^{\prime} \mathrm{OH} \leftrightarrow$ $\mathrm{RCOOR}^{\prime}+\mathrm{H}_{2} \mathrm{O}$ ), in which sulfuric acid dehydrates the medium and removes the water of condensation thereby shifting the esterification reaction to the right-hand side (of ester formation). The hypothetical reaction and schematic description for the proposed colorimetric method is shown for JWH-018 as a representative compound in Fig. 2.

The formation of bis(indolyl) alkanes from the indole containing-organic molecules in the presence of an aldehyde (such as $p$-DMAB) can be supported by Ehrlich reaction-based organic syntheses in the literature. ${ }^{50,51}$ The proposed structure of bis(indolyl)alkane synthesized from indole derivative and $p$-DMAB with silica-sulfuric acid (SSA) catalysis was shown by Pore et al..$^{47}$ using various spectroscopic techniques such as IR, ${ }^{1} \mathrm{H}$ - and ${ }^{13} \mathrm{C}-\mathrm{NMR}$.

\section{Optimization of reaction parameters}

The results related to the optimization of the reaction parameters were evaluated in Supporting Information. 
Table 1 Analytical performance parameters of the proposed method for the tested synthetic cannabimimetics

\begin{tabular}{|c|c|c|c|c|c|}
\hline Cannabinoid & Linear range $^{\mathrm{a}}$ & Calibration equation & $\varepsilon^{\mathrm{b}}$ & $\mathrm{LOD}^{\mathrm{c}}$ & $\mathrm{RSD}^{\mathrm{f}}, \%$ \\
\hline JWH-081 & $2.5-25$ & $\begin{array}{l}A_{575 \mathrm{~nm}}=5.44 \times 10^{-2} C_{\mathrm{JWH}-081}+6.9 \times 10^{-2} \\
\quad(r=0.9995)\end{array}$ & $\varepsilon_{575 \mathrm{~nm}}=2.21 \times 10^{4}$ & 0.72 & $0.56-3.9$ \\
\hline AM-2201 & $6.25-75$ & $\begin{array}{l}A_{575 \mathrm{~nm}}=1.21 \times 10^{-2} C_{\mathrm{AM}-2201}+6.3 \times 10^{-2} \\
\quad(r=0.9991) \\
A_{635 \mathrm{~nm}}=1.21 \times 10^{-2} C_{\mathrm{AM}-2201}+7.4 \times 10^{-2} \\
\quad(r=0.9990)\end{array}$ & $\begin{array}{l}\varepsilon_{575 \mathrm{~nm}}=4.72 \times 10^{3} \\
\varepsilon_{635 \mathrm{~nm}}=4.90 \times 10^{3}\end{array}$ & $\begin{array}{l}1.56^{\mathrm{d}} \\
1.32^{\mathrm{e}}\end{array}$ & $0.42-5.4$ \\
\hline MAM-2201 & $6.25-37.5$ & $\begin{array}{l}A_{635 \mathrm{~nm}}=2.78 \times 10^{-2} C_{\mathrm{MAM}-2201}-7.0 \times 10^{-4} \\
\quad(r=0.9991)\end{array}$ & $\varepsilon_{635 \mathrm{~nm}}=1.04 \times 10^{4}$ & 1.47 & $0.56-4.0$ \\
\hline JWH-122 & $3-30$ & $\begin{array}{l}A_{635 \mathrm{~nm}}=3.54 \times 10^{-2} C_{\mathrm{JWH}-122}+3.1 \times 10^{-2} \\
\quad(r=0.9994)\end{array}$ & $\varepsilon_{635 \mathrm{~nm}}=1.35 \times 10^{4}$ & 0.64 & $0.14-3.6$ \\
\hline JWH-018 & $3-25$ & $\begin{array}{l}A_{635 \mathrm{~nm}}=3.87 \times 10^{-2} C_{\mathrm{JWH}-018}-9.3 \times 10^{-3} \\
\quad(r=0.9995)\end{array}$ & $\varepsilon_{635 \mathrm{~nm}}=1.30 \times 10^{4}$ & 0.68 & $0.3-0.67$ \\
\hline JWH-210 & $1-10$ & $\begin{array}{l}A_{635 \mathrm{~nm}}=8.68 \times 10^{-2} C_{\mathrm{JWH}-210}+7.7 \times 10^{-3} \\
\quad(r=0.9995)\end{array}$ & $\varepsilon_{635 \mathrm{~nm}}=3.79 \times 10^{4}$ & 0.14 & $0.27-1.2$ \\
\hline XLR-11 & $10-50$ & $\begin{array}{l}A_{575 \mathrm{~nm}}=1.40 \times 10^{-2} C_{\mathrm{XLR}-11}-3.4 \times 10^{-2} \\
\quad(r=0.9988)\end{array}$ & $\varepsilon_{575 \mathrm{~nm}}=4.40 \times 10^{3}$ & 2.66 & $1.2-6.7$ \\
\hline $5 F-P B-22$ & $2.5-15$ & $\begin{array}{l}A_{575 \mathrm{~nm}}=6.70 \times 10^{-2} C_{5 \mathrm{~F}-\mathrm{PB}-22}-3.1 \times 10^{-3} \\
\quad(r=0.9993)\end{array}$ & $\varepsilon_{575 \mathrm{~nm}}=2.46 \times 10^{4}$ & 0.45 & $1.7-4.3$ \\
\hline
\end{tabular}

a. In $\mu \mathrm{g} \mathrm{mL} \mathrm{L}^{-1}$ units at final concentration. b. Molar absorptivity, in $\mathrm{L} \mathrm{mol}^{-1} \mathrm{~cm}^{-1}$ units. c. Limit of detection, in $\mu \mathrm{g} \mathrm{mL}-1$ units $\left(\mathrm{LOD}=3 \sigma_{\mathrm{bl}} / m\right.$, $\sigma_{\mathrm{bl}}$ denoting the standard deviation of a blank and $m$ showing the slope of the calibration line). d. Limit of detection, at $575 \mathrm{~nm}$ for AM-2201. e. Limit of detection, at $635 \mathrm{~nm}$ for AM-2201. f. Relative standard deviation $(N=5)$.

\section{Analytical performance of the proposed method}

The proposed method with the use of silica-sulfuric acid catalyst was applied to the tested cannabimimetics to produce the molecular absorption spectra shown in Fig. S1 (Supporting Information). Four compounds yielded purple and four blue colored products with absorbance maxima at 575 and $635 \mathrm{~nm}$, respectively.

Ehrlich reaction products may naturally have different colors. Ehrlich's reagent will react with simple indoles (tryptophan, 5-OH tryptophan, etc.) acting as nucleophiles, and the color of the condensation products formed between indole and aldehydes may be purple, pink, blue, green to brown, orange, or yellow, and depend on the type of substitution involved. ${ }^{52}$

When indole derivatives with active hydrogens both at C-2position and C-3-position react with Ehrlich's reagent in an acidic medium, a water-soluble colored cation complex is formed ${ }^{53}$ having maximum absorbance at $635 \mathrm{~nm}$ in our case. According to the comments of the same authors, ${ }^{53}$ this bathochromic shift of maximum absorbance wavelength $\left(\lambda_{\max }\right)$ corresponding to blue or blue-violet colored products (compared to pink or pink-purple products having $\lambda_{\max }$ at $575 \mathrm{~nm}$ ) may be visualized as a broader electron delocalization within the $\pi$-system involving greater number of atoms in resonance in the
Ehrlich reaction product.

In this work, the ease of electrophilic substitution of the (aminoalkyl)indole-containing synthetic cannabimimetic, as reflected in the time and temperature of synthesis in silicasulfuric acid (SSA)-catalyzed reaction, as well as possible solvatochromic effects ${ }^{54}$ originating from the use of EtOH or $\mathrm{MeOH}-\mathrm{H}_{2} \mathrm{O}$ as solvents with different polarities, may have played a role in the observed different colors of Ehrlich reaction products. XLR-11 (in $\mathrm{MeOH}-\mathrm{H}_{2} \mathrm{O}$ ) produced a pink color, whereas JWH-081 (in EtOH) gave a blue-violet color; these synthetic cannabimimetics were necessarily tested in different solvents where they were sufficiently soluble.

The analytical performance parameters for each of the tested synthetic cannabimimetics are summarized in Table 1 . The intra- and inter-day precisions were also assessed at three concentrations (low, middle and high) in the calibration range (for details, please see Table S1). As seen in Table S1, the intraday and inter-day precisions were within the range of $0.28-$ 2.12 and $0.35-2.56 \%$, respectively.

Additionally, the colors of all the analyzed synthetic cannabimimetics are shown in the color chart in Fig. 3. This color chart enabling naked eye interpretation of preliminary screening tests may be useful for rapid qualitative analysis. 


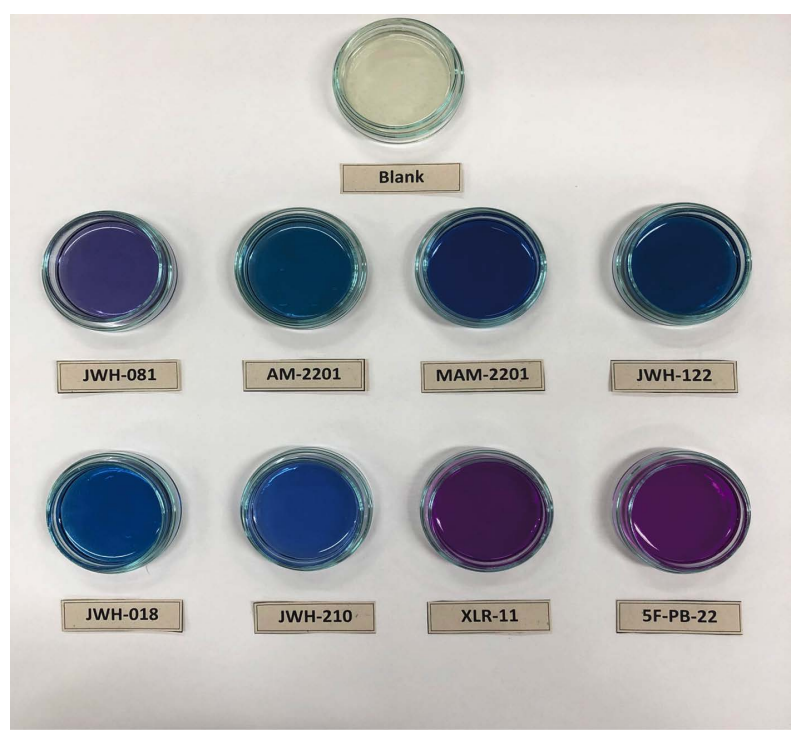

Fig. 3 Color changes of the blank and the analyzed synthetic cannabimimetics $\left(50 \mu \mathrm{g} \mathrm{mL}^{-1}\right.$, final conc.) with the proposed method.

The required reagents and laboratory materials are inexpensive, easy-to-use, and can be applied with minimal personnel training.

The absorbance measurements of the colored products for the tested cannabimimetics can also be made by an Apple iPhone $6 \mathrm{~s}$ Plus smartphone (Cupertino, CA) with colorimeter application, according to the procedure defined by Kuntzleman and Jacobson, ${ }^{55}$ and converted to a calibration line (drawn as absorbance versus concentration) of synthetic cannabimimetics.

Analytical results of the proposed method for synthetic cannabimimetics tested along with commonly used camouflage materials

The method was separately applied to mixtures of AM-2201 with indomethacin, ziprasidone, mannitol, salicylic acid and urea, and the observed recoveries were between 85 - 114\% (for details, please see Supporting Information). Additionally, the proposed method was directly applied to unspiked salicylic acid, urea, mannitol, ziprasidone and indomethacin. The bar diagram (Fig. 4) shows that those camouflage materials that may be carried by passengers as passenger belongings in hand-held luggages had no significant responses (i.e. no false positives).

\section{Results of real sample analyses}

For real sample assay, the proposed method was applied to AM-2201-impregnated plant material, as described in Supporting Information. The calibration equation for this analyte was obtained as: $A_{575 \mathrm{~nm}}=1.21 \times 10^{-2} C_{\mathrm{AM}-2201}+6.3 \times 10^{-2}$, where $C_{\mathrm{AM}-2201}$ is the concentration of analyte in $\mu \mathrm{g} \mathrm{mL}^{-1}$. Using this equation, the final concentration of this synthetic cannabimimetic was found as $1.975 \mu \mathrm{g} \mathrm{mL}^{-1}$. Since the followed procedure required 200-fold dilution, it was deduced that the actual concentration of AM-2201 in the original plant material (Veronica, speedwell) was $395 \mu \mathrm{g} \mathrm{mL} \mathrm{m}^{-1}$.

The proposed method was also applied to JWH-018impregnated plant material. The calibration equation for this analyte was obtained as: $A_{635 \mathrm{~nm}}=3.87 \times 10^{-2} C_{\mathrm{JWH}-018}-9.3 \times 10^{-3}$, where $C_{\mathrm{JWH}-018}$ is the concentration of analyte in $\mu \mathrm{g} \mathrm{mL}^{-1}$. Using this equation, the final concentration of this synthetic cannabimimetic was found as $10.73 \mu \mathrm{g} \mathrm{mL}^{-1}$. Since the followed procedure required 10 -fold dilution, it was deduced

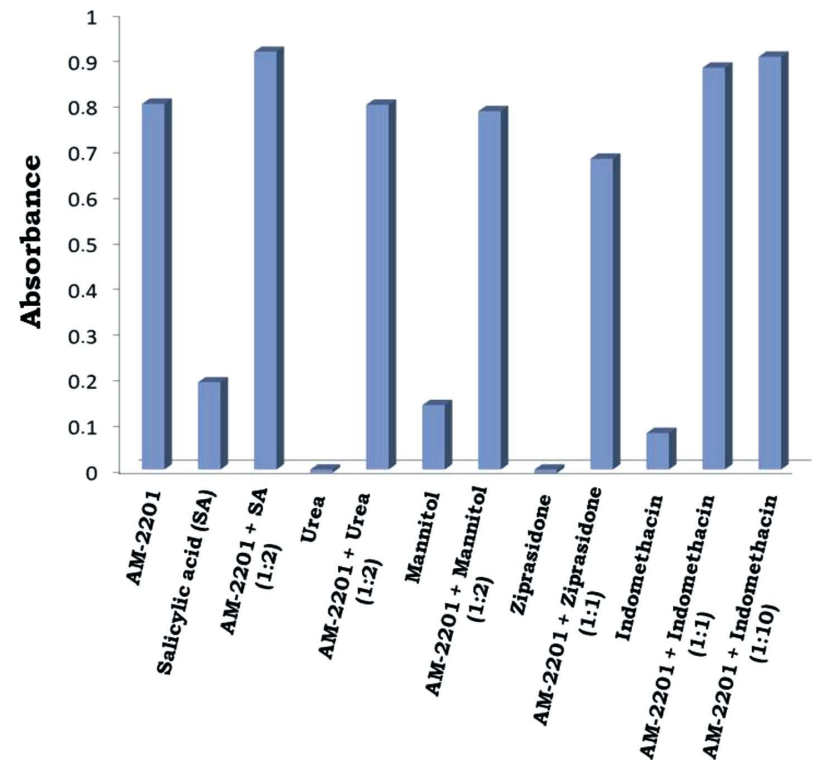

Fig. 4 Responses of $60 \mu \mathrm{g} \mathrm{mL}^{-1}$ AM-2201, $120 \mu \mathrm{g} \mathrm{mL} \mathrm{m}^{-1}$ mannitol, $120 \mu \mathrm{g} \mathrm{mL}^{-1}$ salicylic acid, $120 \mu \mathrm{g} \mathrm{mL}^{-1}$ urea, and mixtures of analyte (AM-2201) with $120 \mu \mathrm{g} \mathrm{mL}^{-1}$ salicylic acid, $120 \mu \mathrm{g} \mathrm{mL}^{-1}$ urea, $120 \mu \mathrm{g} \mathrm{mL}^{-1} \quad$ mannitol, $\quad 60 \mu \mathrm{g} \mathrm{mL}^{-1} \quad$ ziprasidone, $\quad 60 \mu \mathrm{g} \mathrm{mL}^{-1}$ indomethacin and $600 \mu \mathrm{g} \mathrm{mL}^{-1}$ indomethacin to the proposed method. All concentrations were given as final values.

that the actual concentration of JWH-018 in the original plant extract (from dried marshmallow leaves) was $107.3 \mu \mathrm{g} \mathrm{mL}^{-1}$.

LC-MS/MS determination of synthetic cannabimimetics for method validation

The proposed procedure was validated against the reference LC-MS/MS method ${ }^{40}$; the $t$ - and $F$-tests were used for comparing the population means and variances, respectively. The confidence levels used in validation of findings were $95 \%$ for both $t$ - and $F$-tests in both comparisons for AM-2201 and JWH081 (Table S2). The details of LC-MS/MS findings for method validation are included in Supporting Information.

\section{Conclusions}

Owing to the proposed method, a relatively selective and sensitive colorimetric procedure was developed for the first time for the determination of aminoalkylindole-containing synthetic cannabimimetics in single sample analysis. The analytes (AM2201, MAM-2201, JWH-081, JWH-018, JWH-210, JWH-122, 5F-PB-22 or XLR-11) turned into a colored product form (purple or blue) as a result of the electrophilic substitution reaction between $p$-DMAB and aminoalkylindole group, and the color change was detected by UV-Vis spectrophotometry at $575 \mathrm{and} /$ or $635 \mathrm{~nm}$. The method was optimized and analytical figures of merit determined. The proposed low-cost and easyto-use spot test positively responding to the indole group is expected to be useful in pre-screening criminologic analysis. This spectrophotometric method is suitable for single analyte determination with good precision and accuracy.

\section{Acknowledgements}

The authors wish to thank Istanbul Police Directorate, 
Criminology Laboratory (Istanbul Emniyet Müdürlügü, Kriminal Polis Laboratuvari) for enabling access to the laboratory facilities and providing the non-certified synthetic cannabinoid sample. Additionally, one of the authors (B. G.) thanks to TUBITAK (Turkish Scientific and Technical Research Council) for the research project $112 \mathrm{~T} 792$.

\section{Supporting Information}

Supporting information contains: Preparation of solutions, Optimization of reaction parameters for the recommended method, Analytical recovery of synthetic cannabimimetics in the presence of camouflage materials, LC-MS/MS conditions, Real sample analysis, Results of optimization of reaction parameters, LC-MS/MS determination of synthetic cannabimimetics for method validation, Analytical results of the proposed method for synthetic cannabimimetics tested along with commonly used camouflage materials, Fig. S1 and Tables S1 - S2. This material is available free of charge on the Web at http://www.jsac.or.jp/ analsci/.

\section{References}

1. H. Kalant, Pain Res. Manage., 2001, 6, 80.

2. Z. Atakan, Ther. Adv. Psychopharmacol., 2012, 2, 241.

3. J. B. Zawilska and J. Wojcieszak, Int. J. Neuropsychopharmacol., 2014, 17, 509.

4. UNODC, Synthetic Cannabinoids in Herbal Products, https://www.unodc.org/documents/scientific/Synthetic_ Cannabinoids.pdf (accessed 30 November 2017).

5. W. Hall and L. Degenhardt, World Psychiatry, 2008, 7, 68.

6. Q. Zhang, P. Ma, R. B. Cole, and G. Wang, Anal. Bioanal. Chem., 2006, 386, 1345.

7. R. Mechoulam and Y. Shvo, Tetrahedron, 1963, 19, 2073.

8. Y. Gaoni and R. Mechoulam, J. Am. Chem. Soc., 1964, 86, 1646.

9. J. W. Huffman, D. Dai, B. R. Martin, and D. R. Compton, Bioorg. Med. Chem. Lett., 1994, 4, 563.

10. J. A. H. Lainton, J. W. Huffman, B. R. Martin, and D. R. Compton, Tetrahedron Lett., 1995, 36, 1401.

11. J. L. Wiley, D. R. Compton, D. Dai, J. A. H. Lainton, M. Phillips, J. W. Huffman, and B. R. Martin, J. Pharmacol. Exp. Ther., 1998, 285, 995.

12. J. W. Huffman, Curr. Med. Chem., 1999, 6, 705.

13. R. Lindigkeit, A. Boehme, I. Eiserloh, M. Luebbecke, M. Wiggermann, and L. Ernst, Forensic Sci. Int., 2009, 191, 58.

14. J. Y. Shim, E. R. Collantes, and W. J. Welsh, J. Med. Chem., 1998, 41,452 .

15. S. Sugahara, M. Suzuki, H. Kamiya, M. Yamamuro, H. Semura, Y. Senga, M. Egawa, and Y. Seike, Anal. Sci., 2016, 32, 1129.

16. X. Yin, S. Wang, X. Liu, C. He, Y. Tang, Q. Li, J. Liu, H. Su, T. Tan, and Y. Dong, Anal. Sci., 2017, 33, 659.

17. Y. Kong, J. Shen, and A. Fan, Anal. Sci., 2017, 33, 925.

18. N. Sui, F. Liu, T. Li, L. Wang, T. Wang, M. Liu, and W. W. Yu, Anal. Sci., 2017, 33, 963.

19. UNODC, Recommended Methods for the Detection Assay of Heroin, Cannabinoids, Cocaine, Amphetamine and RingSubstituted Amphetamine Derivatives in Biological Specimens, https://www.unodc.org/documents/publications/ report_assay_1995-09-01_1.pdf (accessed 30 November 2017).

20. UNODC, Rapid On-Site Screening of Drugs of Abuse,
https://www.unodc.org/pdf/scientific/Scitec18_final1.pdf (accessed 30 November 2017).

21. UNODC, Recommended Methods for the Identification and Analysis of Amphetamine, Methamphetamine and Their Ring-Substituted Analogues in Seized Materials, https:// www.unodc.org/documents/scientific/stnar34.pdf (accessed 30 November 2017).

22. UNODC, Recommended Methods for the Identification and Analysis of Cannabis and Cannabis Products, https:// www.unodc.org/documents/scientific/ST-NAR-40-Ebook_1.pdf (accessed 30 November 2017).

23. UNODC, Colour Tests for Precursor Chemicals of Amphetamine-Type Substances https://www.unodc.org/ documents/scientific/SCITEC21_07fin.pdf (accessed 30 November 2017).

24. Color Test Reagents/Kits for Preliminary Identification of Drugs of Abuse https://www.ncjrs.gov/pdffiles1/nij/183258.pdf (accessed 30 November 2017).

25. UNODC, Colour Tests For Precursor Chemicals of Amphetamine-Type Substances, https://www.unodc.org/ pdf/scientific/SCITEC20-fin.pdf (accessed 30 November 2017).

26. Colour Tests and Analytical Difficulties with Emerging Drugs of Abuse, https://www.nist.gov/sites/default/files/ documents/oles/Color-Tests-and-Analytical-Difficultieswith-Emerging-Drugs-Morris.pdf (accessed 30 November 2017).

27. B. K. Logan, L. E. Reinhold, A. Xu, and F. X. Diamond, J. Forensic Sci., 2012, 57, 1168.

28. A. Namera, M. Kawamura, A. Nakamoto, T. Saito, and M. Nagao, Forensic Toxicol., 2015, 33, 175.

29. R. C. A. Isaacs, Forensic Sci. Int., 2014, 242, 135.

30. N. Uchiyama, R. Kikura-Hanajiri, J. Ogata, and Y. Goda, Forensic Sci. Int., 2010, 198, 31.

31. F. Westphal, F. D. Sönnichsen, and S. Thiemt, Forensic Sci. Int., 2011, 215, 8.

32. K. Zaitsu, M. Katagi, K. Nakanishi, N. Shima, H. Kamata, T. Kamata, H. Nishioka, A. Miki, M. Tatsuno, T. Iwamura, T. Sato, H. Tsuchihashi, and K. Suzuki, Jpn. J. Forensic Sci. Technol., 2011, 16, 73.

33. H. J. Penn, L. J. Langman, D. Unold, J. Shields, and J. H. Nichols, Clin. Biochem., 2011, 44, 1163.

34. N. Uchiyama, S. Matsuda, M. Kawamura, Y. Shimokawa, R. Kikura-Hanajiri, K. Aritake, Y. Urade, and Y. Goda, Forensic Sci. Int., 2014, 243, 1.

35. V. Shevyrin, V. Melkozerov, A. Nevero, O. Eltsov, A. Baranovsky, and Y. Shafran, Forensic Sci. Int., 2014, 244, 263.

36. K. Sekuła, D. Zuba, and R. Stanaszek, J. Mass. Spectrom., 2012, 47, 632.

37. J. Nakajima, M. Takahashi, R. Nonaka, T. Seto, J. Suzuki, M. Yoshida, C. Kanai, and T. Hamano, Forensic Toxicol., 2011, 29, 132.

38. K. Hasegawa, A. Wurita, K. Minakata, K. Gonmori, I. Yamagishi, H. Nozawa, K. Watanabe, and O. Suzuki, Forensic Toxicol., 2015, 33, 112.

39. A. Ehmann, J. Chromatogr., 1977, 132, 267.

40. Shimadzu Application, Quantitative Analysis of Cannabinoids Using the LCMS-8040 Triple Quad MS, https://www.shimadzu.de/sites/default/files/dr08_analysis_ of_designer_cannabinoids_using_lcms-8030.pdf (accessed 26 April 2018).

41. R. Sedefov, A. Gallegos, L. King, D. Lopez, V. Auwärter, B. Hughes, and P. Griffiths, "Understanding the 'Spice' Phenomenon", 2009, Office for Official Publications of the European Communities, Luxembourg.

42. T. Kurata and Y. Sakurai, Agric. Biol. Chem., 1967, 31, 170. 43. H. Reich, K. F. Crane, and S. J. Sanfilippo, J. Org. Chem., 
1953, 18,822 .

44. G. G. Glenner, J. Histochem. Cyctochem., 1957, 5, 297.

45. G. G. Glenner and R. D. Lillie, J. Histochem. Cytochem., 1957, 5, 279

46. J. Clayden, N. Greeves, and S. Warren, "Organic Chemistry", 2nd ed., 2001, Oxford University Press, New York, ISBN: 978-0-19-927029-3.

47. D. M. Pore, U. V. Desai, T. S. Thopate, and P. P. Wadgaonkar, Arkivoc, 2006, 12, 75.

48. M. Chakrabarty, N. Ghosh, R. Basak, and Y. Harigaya, Tetrahedron Lett., 2002, 43, 4075.

49. B. Maleki, H. K. Shirvan, F. Taimazi, and E. Akbarzadeh, Int. J. Org. Chem., 2012, 2, 93.
50. P. Ehrlich, Med. Woche, 1901, 151.

51. V. T. Kamble, K. R. Kadam, N. S. Joshi, and D. B. Muley, Catal. Commun., 2007, 8, 498.

52. E. J. Staba and K. L. Su, Aquatic Plants from Minnesota Part 1-Chemical Survey (Bulletin 46), 1972, Water Resources Research Center, http://purl.umn.edu/92137 (accessed 07 August 2018).

53. Q. Jin, L. Shan, J. Yue, and X. Wang, Food Chem., 2008, $108,779$.

54. E. Buncel and S. Rajagopal, Acc. Chem. Res., 1990, 23, 226.

55. T. S. Kuntzleman and E. C. Jacobson, J. Chem. Educ., 2016, 93, 1249. 